\title{
WHERE HAVE ALL THE GARDENS GONE?
}

\section{Tony Hall, URP Griffith University}

The disadvantages of the low-density car-based suburbs that surround Australian and American cities are well known and widely debated. These include facilities located to the disadvantage of non-car users, wasteful use of land, cost of infrastructure, time and energy expended on driving, low incidence of social contact and lack of exercise. Nevertheless, the older Australian suburb also has compensating advantages for both the residents and the wider community. One is a generally high degree of bio-diversity. The presence of trees also provides shade, modifying the microclimate and giving aesthetic pleasure. The planted areas around the dwelling also aid the process of storm drainage by retaining water and reducing run-off. The private amenity space around the dwelling can accommodate not just a garden for the pleasure of the occupants but also barbeque facilities and an in-ground swimming pool. These not only benefit the residents directly but also facilitate social interaction with friends and neighbours. In many parts of Australia, notably Queensland, use is made of verandas to provide outdoor living sheltered from the sun. Although the roofs may be very large, a significant part of the space under them is open to the air and to the surroundings.

The more recent suburbs, however, display a disturbing trend. The dwelling now extends near to the boundary of the plot and, in consequence, near to adjoining dwellings. There is very little private amenity space to the rear of the dwelling, in extreme cases none at all. There is little in the way of balconies and verandas. Windows are often small and tinted. The design is square or deep-plan and incorporates an integral double garage further reducing the scope for natural lighting and ventilation. Usually, only one room provides an outlook to the front and surveillance of the street. While the disadvantages of suburban living still apply, the advantages referred to above have disappeared.

\section{A quantitative analysis}

To try to obtain an understanding of what has been happening a quantitative analysis of sample areas of Australian cities has been undertaken by the author. Comparisons were also made with selected examples in the USA. A full report of the findings is available (Hall, 2007).

A visual inspection of aerial photographs of urban areas was made using Google Earth. It concentrated on the state capitals, with the exception of Hobart. The different types of form being investigated stood out clearly and occupied contiguous areas. It was possible to identify recent construction by virtue of the different colour of the roads and other paving. What was immediately striking was the clear difference between the older suburban areas with their large gardens and tree cover and newer ones where there was little in the way of private amenity space.

Figure 1 shows an aerial view of part of the Gold Coast in South East Queensland, around the suburb of Labrador. The contrast between the left and right hand sides of the picture was immediately noticeable. On the right were the comparatively older residential areas with modest dwelling footprints and significant tree cover. On the left were the newer developments with large dwelling footprints and few trees.

Figure 2 shows an aerial view of part of the suburb of Spearwood a southern suburb of Perth, just over $17 \mathrm{~km}$ south of the city centre. The comparatively older development is on the right and the newer on the left. Although the house 
footprints in the older development were fairly large, the difference between the two types of urban form was again clear.

This pattern of development was widespread in all the cities studied except Adelaide. What was especially significant here was the disjunction in both space and time. There was no evidence of gradual change. Although there was variation in the detailed dimensions of the plots and dwellings, the two types of form stood out as uniform phenomena. Before a certain date, suburban form had incorporated back gardens of useful size and shape and a significant coverage of trees. After this date, these were absent.

The results of the survey of the older suburbs are shown by Table 1 . The first area studied was the suburb of Camp Hill, $5.7 \mathrm{~km}$ southeast of the centre of Brisbane. The houses were generally of the "Queenslander" type, the vernacular architecture of the State. The second was part of the Melbourne suburb of Kew East, just over $9 \mathrm{~km}$ from the city centre. The third was Herbersham, near Mount Druitt, some $38 \mathrm{~km}$ west of the centre of Sydney. The fourth was part of the Perth suburb of Spearwood, to on the right side of the view shown by Figure 2 .

The results of the survey of the newer suburbs studied are shown by Table 2 . The first row refers to the Gold Coast suburb of Labrador in the lower left of the view shown by Figure 1. This had the lowest net density, $10.5 \mathrm{dph}$, of all the newer Australian developments studied which was lower also than all but one of the older suburbs studied. Nevertheless, the back-to-back distances were only $3-4 \mathrm{~m}$, leaving only $1.5-2.0 \mathrm{~m}$ at the back of the house. At $720-825 \mathrm{~m}^{2}$, the plot areas were larger than most of the plots in the older suburbs studied.

It was the extreme design of a scheme in Carina, a suburb of Brisbane lying 8.5 $\mathrm{km}$ south east of the city centre, that had originally triggered this investigation. The private amenity space to rear and sides of the dwellings was near to nonexistent. The forward position of the double garages, combined with the use of small, tinted windows, created a blank townscape with a lack of transparency and surveillance, as shown by Figure 3 .

A gated estate of two-storey houses within the Brisbane suburb of Hendra was studied. An aerial view is shown by Figure 4. Because they were two-storey, the dwelling footprint was the smallest and the net density, $30 \mathrm{dph}$, the highest of all the examples studied. Although, being two storey, they gained more light and air than the other examples studied, they did not enjoy back gardens, the distance at the back of the house ranging from $3 \mathrm{~m}$ to less than one.

The other site studied in Hendra was the line of houses that can be seen at the top of the view shown by Figure 4 . They were all single storey and formed the first stage of a larger development. At $21 \mathrm{dph}$, the density made an interesting contrast with gated estate immediately to the south. The houses generally had only $2-3 m$ at the back, sometimes even less.

Forest Lake was distinguished from the other examples studied in that most, but not all, of the dwellings had a space with some trees at the rear. However, these spaces were not commensurate with the size of the house, nor comparable to the back gardens in the older suburbs

Two examples in the in Mount Druitt in the western suburbs of Sydney were selected. The first was part of Rooty Hill, nearly $38 \mathrm{~km}$ from the city centre. It is $3 \mathrm{~km}$ south east of the older Herbersham area in Table 1. An aerial view is shown by Figure 5 . What was immediately striking was that, not only were the houses square deep-plan with very little space around them, but that some of the houses were almost completely surrounded by others, an arrangement often 
referred to as a "battleaxe" layout. The limited space at the front of one of these properties is shown by Figure 6.

The second example was off Meacher Street in Mount Druitt. Here, the 31 houses were arranged in two parallel culs-de-sac. Some houses were comparatively modest in scale and, unusually, shallow plan in form which permitted a minimally sized outdoor space at the rear. However, 18 of the dwellings were large deep-plan houses, with near zero space at the rear.

The example studied in Perth was a recent extension of the suburb of Spearwood, on the left of the area shown by Figure 2. What was remarkable here was the low density and large plot sizes, as with the Gold Coast example. At $13.6 \mathrm{dph}$ the density was nearer to the older suburbs than to most of the other recent examples but this did not result in the same amount of green space. At around $600-700 \mathrm{~m}^{2}$, the plots were larger than for the other new suburbs studied but so were the house footprints. The back-to-back distances were generally only $3-5 \mathrm{~m}$ with some being near zero. Some of the houses were almost entirely surrounded by others.

\section{Overseas comparisons}

Searches for examples of this phenomenon were made outside of Australia in countries with comparable patterns of suburban development. However, it proved difficult to find similar examples in both North America and New Zealand.

To provide a more detailed basis for comparison, three examples of recent outer suburban development in the US were collected and measured. The results are shown by Table 3. The first was from the outskirts of Columbus, Ohio, a city often taken as typical of middle America. The second example was from Rocklin CA, on the outskirts of Sacramento, selected as typical of the West Coast, where a somewhat older suburb had been recently extended. The third example was part of Sun City AZ, on the outskirts of Phoenix, often cited in planning literature as one of the most remarkable examples of the "edge city". The results are shown by Table 3. Dwelling footprints were large, as in Australia, but so were the plot areas. For all three examples, the house footprints occupied, in general, approximately $30 \%$ of the plot area.

\section{Overview}

Comparing the old and new Australian examples we can note an increase in net residential density from 9-13 dph to 13-20 dph and an increase in plot coverage from $30 \%$ to $50-70 \%$. Although the picture for plot size and dwelling footprint was complex, because of the ranges of shapes and sizes, it appeared that, in general, the plot size had been getting smaller and the dwelling footprint larger. However, in the Gold Coast and Perth examples the plot areas there were generally larger and the densities lower. What was remarkable there was that, although plots were comparable, or larger than, those in the older suburbs of Sydney and Brisbane, they were almost completely covered by larger dwellings.

The international comparisons suggested that the phenomenon was very much an Australian one. This was illustrated starkly by the plot coverage statistics in the Tables. Both the new American suburbs, and the older suburbs in Australia. showed one-third coverage or less, despite widely differing circumstances. In the American examples, the house footprints were marginally larger but the plot areas were significantly larger. This permitted a rear private amenity space equivalent in area to the older Australian suburbs. 


\section{Why should this disappearance be a problem?}

It may be useful to start by reflecting on the functions of private gardens and yards in residential layouts. They are not limited to the quality of life of individual households but also bring benefits to the wider community. These wider benefits arise from the presence of trees, other planting and soft surfaces.

Trees not only provide shade from the sun but also modify the microclimate and absorb pollutants. The soft surfaces absorb rainwater and reduce run off into drains. They form the first stage in a system of sustainable drainage. Trees need space to grow both for the canopy and, most importantly, the roots. Structural damage to buildings by roots needs to be avoided. The reduction of space around the dwellings has the effect of substantially reducing the degree of tree coverage in perpetuity, as there will be no room for them to the sides and backs of the houses.

Private gardens exhibit a high degree of biodiversity. When aggregated over a residential area this diversity can be very significant and in excess of that found, for example, on land devoted to sports fields or intensive agriculture. It is not necessary for the whole of each garden to be soft landscape for this benefit to accrue as long as there is an interplay of hard and soft landscaping within each plot.

Regarding the quality of life of the residents, one of the most important roles of the space around the house is to provide outlook, natural light and natural ventilation. These amenities are enjoyed even if the occupants never venture outside.

A garden or yard to the rear of the property offers the advantages of security and privacy not found in public space and can be characterised as an outdoor room. It can provide a space for small children to play in secure surroundings and where they can be supervised by adults from inside adjoining rooms. It also provides a place for adults to sit out and to dine outdoors, an activity that might be considered very appropriate in the Australian climate. It provides space for barbecue facilities and in-ground swimming pools both of which have often been characterised in the past an important features of the Australian way of life. For the pursuit of a sustainable lifestyle, back gardens and yards provide space for:

- drying laundry without the use of electricity;

- water collection and storage;

- waste disposal (composting, sewerage disposal, etc.),

- home food production (as a supplement, not a replacement, to foodstuffs purchased outside the home).

\section{Reduction of plot coverage}

Tables 1 and 2 show the increase in plot coverage by dwellings from $30 \%$ to 50 $70 \%$. At first glance, this may not seem too problematic. Half of a $600 \mathrm{~m}^{2}$ plot would be $300 \mathrm{~m}^{2}$ and $70 \%$ would be $180 \mathrm{~m}^{2}$. However, this neglects two factors. The first is the effect of the small space left to the sides of the dwelling. Imagine a house footprint with a $2 \mathrm{~m}$ gap all around it. (This ought to be seen as a hypothetical exercise but it does correspond to some of the cases observed at Rooty Hill.) For a $300 \mathrm{~m}^{2}$ plot area, say $10 \times 30 \mathrm{~m}$, this gives a plot coverage of $52 \%$. For a $600 \mathrm{~m}^{2}$ plot area, say $15 \times 40 \mathrm{~m}$, the coverage is $66 \%$. To limit, therefore, a dwelling to half the area of a plot will not ensure, in itself, any useful private amenity space.

This problem is compounded when the space at the front of the dwelling is taken into account. A front set-back of the dwelling from the front boundary of the plot, facing the road is required in most of Australia. Once this is removed from the 
$30-50 \%$, then very little remains elsewhere. As Tables 1 and 3 show, a useful area at the back of the house is associated with a plot coverage of around $30 \%$.

\section{The role of plan form}

The issue of private gardens provision is linked to that of the shape of the planform of the dwelling. A square plan, needs a large plot to provide a good-sized garden and will be a satisfactory arrangement only for very low-density layouts of detached houses. The deep plan arrangement, is popular with developers as they can fit more dwellings into a given length of road. It makes garden provision very difficult as any reasonably sized area becomes long and narrow. Both the deep-plan and large square-plan forms have interior sections that are difficult to light and ventilate naturally (other than single storey flat roofed dwellings with skylights and interior courtyards). However, from a builder's point of view, the fact that they minimise wall length and fenestration for a given area reduces costs.

With a deep-plan layout, the dwellings have small windows and rarely have balconies and verandas. Their design relies on air conditioning for them to be habitable. However, even if they had been designed for natural ventilation, the reduction in width between the dwellings would make it very difficult, especially in those parts of Australia with subtropical climates. A study (Su San Lee, 1998) of suburban development in the Douglas area of Townsville revealed that the narrowness of the gaps between the houses prevented airflow around them creating a "heat island effect". This was exacerbated by exhausts from the air conditioners and dark coloured roofs which absorbed, rather than reflected, the heat. The use of impervious sheet metal fencing, rather than, open link fencing, was also a factor in reducing airflow. These findings were confirmed by numerous complaints from the residents (Clark, 2006).

In contrast, the shallow and L-shaped plan forms facilitate useful square-shaped private rear spaces. They also provide natural light and ventilation, and maximise outlook, for all rooms. They provide space for detached garage as and garden sheds. When applied over large areas, the shallow depth reduces block depth and thereby enables economic numbers of dwellings to be accommodated.

\section{Garage location}

Integral garages create problems that are closely associated with these issues especially where they are designed for two cars side by side. They have no windows and, consequently, the natural light and ventilation for the interior of the dwelling is substantially reduced. Such provision normally permits only one room, and therefore limited window area, to have outlook to the street. This reduces the aesthetics and security of the public realm.

On the other hand, the provision of space around the dwelling allows cars to be accommodated in detached garages, ideally to the rear, or in carports, avoiding the need for an integral garage. This frees more wall space for windows. This is important at the front of the dwelling as it offers maximum surveillance of the street, adding to the security and aesthetics for passers by. It also benefits the quality of life of the residents as the windows offer the opportunity for natural light and ventilation.

The integral garage is also linked to the issue of large setbacks in front of houses. Such garages are normally at the front of houses and local regulations require space for manoeuvring and parking of at least one car length in front of the garage door. On the other hand a detached garage, which can be linked to the house, or car-port can be set back at the side of the house enabling the house to be set nearer to the road. 


\section{A European perspective}

It is sometimes suggested that the minimisation, or even elimination, of back yards and gardens is a necessary consequence of moves to higher residential densities resulting form policies of urban containment and consolidation. However, not only does the data in Tables 1 and 2 show no direct correlation, but the European experience is that that there need be no direct connection between lack of provision of private amenity space at densities up to $70 \mathrm{dph}$.

In northwest Europe the type of low-density suburban development found in North America and Australia does not occur, although large-scale house building does. New suburban housing schemes without private open space cannot be found because they are not allowed. All the density ranges in Tables 1 and 2 would be regarded as very low and associated with landscape-dominated layouts. Significant back gardens are provided at net densities two to three times those found in the Australian suburb. For example, government policy has raised the density for new construction in England to a minimum of $30 \mathrm{dph}$. Nevertheless back gardens of $150 \mathrm{~m}^{2}$, something found only in the lowest density Australian suburbs are regularly achieved at densities in excess of this figure.

\section{Why is it happening?}

What has been the cause of this abrupt change? Why is it happening? Is it a response to changing patterns of consumer demand? These are important questions but providing an answer is a complex task.

The statistics at the macro level (ABS, 2005) show a substantial rise in the floor area of new houses over the last 20 years. From a figure of $162.2 \mathrm{~m}^{2}$ in $1984-5$, by $2003-4$ the average floor area had risen to $227.6 \mathrm{~m}^{2}$, an increase of $40 \%$. The increase in the ten-year period from $1993-4$ to $2003-4$ was just over $20 \%$. The average site area also declined over the same ten-year period, from $802 \mathrm{~m}^{2}$ in 1993-4 to $735 \mathrm{~m}^{2}$ in $2003-4$ (ABS, 2004). However, the evidence presented in this paper suggests that it has been the increase in the dwelling area, rather than the decrease in the site area, that has been driving the disappearance of back yards and gardens.

\section{Is it consumer choice?}

The first evidence that the disappearance of back yards may not have been a straightforward response to changing household preferences was the clear discontinuity in space and time. Normal markets take time to adjust and variations in preferences can take time to work through. However, what we see is that, after a certain point in time, the construction of one type of suburban form was almost totally replaced by another. In effect, the building of houses with significant gardens ceased within large-scale housing developments. Changes in public taste would be expected to be more gradual with local variations.

A piece of evidence that would suggest a continuing public interest from a significant sector of the public in views and outdoor amenities is the market in city-centre and inner-city residential property. This is just the location where it might be expected that they would be least important. High land values would be expected to mitigate against swimming pools and barbeque facilities. In the past, purchasers would have been expected to accept less, or more likely no, outdoor facilities because of the advantages of a central location. In reality the opposite is now happening. It is the older blocks that have no swimming pools and terraces for barbeques. The newer apartment complexes not only sport these features but have increasingly larger "entertaining balconies" and floor to ceiling windows that take maximum advantage of views. Advertisements for houses in inner suburbs stress the advantages of views. 


\section{An economic explanation?}

The evidence from observers of the situation in the US is that in circumstances of extensive car-borne "sprawl", prospective house buyers drive to a distance where land prices are at level they can afford (Levine, 2006). The further they drive from major centres the lower the prices. This is pattern of behaviour facilitated by the low costs of private transport. With the presence of the same type of "sprawl" in Australia, it is plausible that the same purchaser behaviour would be found here too.

A particular characteristic of the contemporary Australian housing market (and one that can also be found in the US) is the separation of purchase of the plot and the dwelling. (This is not found in Europe where developers build the houses and sell house and plot together as one item.) Prospective purchasers drive to a locality where they can afford the price of a plot. Having selected their plot, they approach a builder who is offering standard house designs. Their perception is that it is to their financial advantage to maximise the resale value of their house and this means maximising its floor area. However, they wish to do this for the lowest initial outlay. They therefore seek the maximum floor area for the minimum price. This objective, pursued in the absence of other considerations, such as running cost or quality of life, leads inexorably to this particular house types and urban layouts that we now see.

The building firms are, by and large, not technically sophisticated and do not offer imaginative designs. They respond to the situation in which they find themselves. Their response to consumer demand for the largest floor area for the lowest price, results in particular design features:

- single storey

- large integral garage

- deep square or rectangular plan form.

The deep square or rectangular plan form minimises the wall length and fenestration for a given area which, consequently, reduces costs. The integral garage is a very cheap structure which is counted as part of the floor area of the dwelling. Styling, ornament and landscaping is concentrated on the front of the house where it has greatest impact on prospective purchasers. This is the house type that predominated in nearly all the examples of new suburbs studied.

\section{Why are the houses an acceptable purchase?}

Notwithstanding the point made above about the demand for views and outdoor facilities in recent city-centre developments, the fact remains that people do choose to live without them in the suburbs in spite of the disadvantages. This is an important point and one that must be addressed. There is, at the very least, an apparent lack of consumer resistance to the trends described. The same could be said about the other characteristics of the "edge city" living which have become almost a commonplace. They include excessive car use, disadvantages to non-car owners such as children, reduced exercise leading to health problems and reduced casual social contact. Residents of the outer suburbs do not rate these problems as significantly as do environmental commentators and may even perceive them as advantages. It may be that they will change their views over time. Regarding the suburban form criticised here, it is certainly a possibility that residents may not find it as satisfactory as they first thought and as the new suburbs become down-market with age the residents may move on to something new.

An argument that has been put to the author is that the occupants of the houses do not, in reality, spend much time at home during the daytime. The lack of any outlook, probably the most serious disadvantage for day-to-day amenity, is not, 
therefore, experienced. However, far from this arising from the pursuit of an outdoor lifestyle, it results from long working hours and commuting times. The occupants leave for work early in the morning and return in the evening. Weekends, when not spent at work, are devoted to many hours of shopping. There is, regrettably, considerable evidence that, for a majority of Australians, this pattern of work is, indeed, the case. The Relationships Forum Australia (2007) has assembled a substantial amount of evidence form a range of official statistical sources that portrays a convincing picture. Their conclusion was:

"Working patterns have altered to such an extent that Australia is now the only high-income country in the world that combines:

- average working hours that are at the top end amongst highincome nations

- a strong tendency for work on weeknights and weekends, and

- a relatively large proportion of the working population employed on a casual basis."

An equivalent message has been delivered by Australian Human Rights and Equal Opportunities Commission (2007). It would appear, therefore, that physical form described in this paper fits all to well into a wider picture of adverse changes in Australian lifestyles.

\section{What has been written?}

Regrettably, the number of studies of the use of private amenity space is very few whatever country is chosen. For Australia, the principal study, The Quarteracre Lot (Halkett, 1976) is now some decades old. It does, however, confirm the importance and usefulness of back garden to its owners. A study by Gutteridge, Haskin \& Davey (1989) found general satisfaction with lot sizes but a desire for more outdoor space by those with smaller lots of $350-450 \mathrm{~m}^{2}$. An unpublished undergraduate study by Brindley (1999) also confirmed the utility and significance of the back yard for residents. A recent general history (Sims, 2006) has reiterated its importance in the Australian tradition. Researchers in landscape studies have noted that trends to smaller lots have not reduced interest in back gardens nor have they been the cause of increased visits to wetlands in Perth (Syme, Fenton \& Cokes, 2001). The most significant study for the purposes of this paper has been that by Mead (2000) which was, unfortunately, unpublished at the time of writing. In 2000 he surveyed one residential areas in each of three suburbs $21-26 \mathrm{~km}$ southeast of Sydney.

What is interesting from the available literature is not just what is said but what did not come out. There were no responses from residents saying that that they disliked back yards and wished to be relived of the burden of maintaining them. Quite the opposite appears to have been true. No sources that Mead discusses, either in Australia or other countries, give this impression. Moreover, the most recent history of Australian domestic gardens (Sim, 2006) continues to argue that they are part of an Australian tradition. If there has been a dramatic change of public mood against back gardens in line with the physical changes in Australian suburban form, then no academic observer has managed to detect it.

\section{Why is it allowed?}

Why is the problem not prevented by the regulations and codes? There will be, of course, variation in the scope and in the details of plans regulatory instruments across the many planning authorities in Australia. One reason for choosing examples from a number of cities was to hopefully take in a range of regulatory regimes. What was remarkable was the widespread occurrence of the phenomenon. 
They generally specify minimum distances from the building to the plot boundaries and the setback at the front. The disadvantage of this approach is that it cannot be linked to these objectives, or at least, not very easily. If distances were measured from building to building rather than to plot boundaries, this would have the advantage of being able to connect the standards to the urban design objectives which relate to spaces between buildings.

Nevertheless, even allowing for these limitations, the regulations could ensure back garden provision by specifying rear set-backs in the same way that front set-backs are required. Most sets of regulations specify minimum distances from buildings to plot boundaries. The issue is how large they are on the rear boundary. Similarly, planning regulation may make reference to site coverage.

However, what is written down in plans and regulations is only part of the story. There can be variations in the strictness and in the style of enforcement. There can variations in interpretation. Positive advice and negotiation can also play a very significant role if need be. What appears to have been happening is that local councils have been taking a more relaxed attitude to plot coverage. This is the most plausible explanation of the move from $30-40 \%$ to $50-60 \%$, or more, and of the way that this trend has become both uniform and seemingly irreversible.

\section{What can be done?}

\section{The justification for intervention}

One objection that is often made to doing anything at all is that any intervention would interfere with individual consumer choice. The immediate response to this is the fairly obvious one that there are advantages that are not related to do individual preferences but to the general public good. The benefits the provision of private open space behind dwellings brings to the wider community include:

- aesthetic townscape;

- biodiversity;

- amenable microclimate, including shade in hot weather;

- absorption of run-off in wet weather.

In other words, it is part of an environment whose sustainability and quality affect everyone, not just the individual residents.

There is also the issue which, within public policy, is peculiar to town planning, the desirability of the long-term robustness of urban form. Dwellings are not like other consumer products such clothes, household appliances, home entertainment, even furniture. They last very much longer. They may last for at least 60 years and, possibly, many centuries. The road layouts may last as long, if not longer. Well-planned housing schemes should be designed to be robust over time. In other words, they should be able to adapt to changing patterns of use without major reconstruction. While it may difficult for a particular urban form to necessarily promote a particular activity, it is very easy for it to prevent something. For example, a housing layout cannot, of itself, guarantee that a bus service will be provided but it can make such provision very difficult or even impossible. The argument against the absence of private open space behind dwellings should not turn on whether or not people want to make use of at present. The argument is that it rules out this use permanently. Large areas of suburban housing have been built, and continue to be built, that can never possess the outdoor facilities that this space permits. Similarly, view and outlook are not benefits that can be retrofitted at a later date without widespread demolition. It would also be difficult to retrofit natural light and ventilation to single-storey deep-plan or square-plan houses. Even if current residents do not want an outlook, garden, swimming pool or barbeque terrace why should these amenities be ruled out in perpetuity? 


\section{Action through the planning system}

A general characteristic of the planning systems of both North America and Australasia, when compared to those of Europe, is that although there may be a reluctance to intervene in the design of development they nevertheless possess plentiful regulations for its control. There is therefore scope for design intervention through the planning system in Australia if there is a political will and if it can be appropriately steered and focused.

Ideally, there should be moves to achieve a far higher standard of residential design on a comprehensive basis, so that the issue of the provision of private amenity space is considered alongside all the other properties of a dwelling. European experience suggests that this can be achieved if there is detailed guidance, consistency of policy over a wide area, consultation with developers at an early stage and, ultimately, the threat of compulsion. It must be remembered there that current trends in Australian suburban house design, in particular the single-storey deep-plan house built on a concrete slab, are comparatively recent in historical context. Rather than constitute some radical departure, promotion of quality of design could represent more of a return to traditional Australian values. It should be emphasised that this something that could apply at all densities and locations.

Even in the absence of a comprehensive approach, there is a much that could be done merely by adjusting quantities within existing regulations. If maximum plot coverage was set at 35\% then the evidence discussed in this paper shows that the problem would effectively be solved. To achieve the amount of floor space that they do at present, purchasers would have to pay more and build to two storeys. Failing this, they would have to accept less floorspace. However, the indications are that the have no functional need for this floor area, nor does it benefit their lifestyle, rather it is pursued as a financial investment. If the policy was applied uniformly, then expenditure on two storeys would still represent an investment.

Failing a restriction on maximum plot coverage, merely specifying a minimum distance from the back of the dwelling to the rear plot boundary of, say, $8 \mathrm{~m}$, would make a significant difference. For a $10 \mathrm{~m}$ wide plot it would give $80 \mathrm{~m}^{2}$ back yard and at wider plots approximately $100 \mathrm{~m}^{2}$ or more. This was the actual provision for some of the houses in some of the examples studied. It should also be noted that current front set-backs normally result in fairly large, planted, front gardens, a circumstance which appears to be accepted by all parties.

\section{Conclusion}

Within the past 10 years, significant private amenity space has largely disappeared from the rear of new suburban houses in Australia. This has been characterised by an increase in plot coverage from $30-40 \%$ to $50-60 \%$ or even more. The change appears both permanent and uniform. It is to be found in all major Australian cities, except Adelaide. It appears to be confined to Australia. In other parts of the world where back gardens have been standard features, North America, New Zealand, Northwest Europe, this trend is not to be found. The outer suburban landscape in Australia has ceased to be one of large gardens with trees. Such landscapes are now confined to the inner suburbs.

With the disappearance, or minimisation, of the private space to the rear of dwellings, all the functions and advantages associated with it also disappear. In summary, the following disadvantages are suffered by the wider community:

- reduced aesthetics;

- reduced surveillance of the public realm; 
- little or no biodiversity;

- poor microclimate, including loss of shade, in hot weather;

- increased run-off in wet weather.

The residents themselves also lack the space for the following:

- sitting out in private;

- secure outdoor children's play;

- provision for swimming, barbeques;

and suffer from:

- drying laundry and other components of a sustainable lifestyle;

- lack of pleasant outlook from windows;

- dark interiors;

- lack of natural ventilation;

- increased electricity consumption.

The design implies an entirely indoor lifestyle, insulated from the prevailing climate and with little opportunity for exercise.

The shift away from back yards represents a loss that has serious ecological implications. It also raises important questions about lifestyles changing for the worse, a trend rendered permanent by the changes to the housing stock.

This phenomenon does not result from urban consolidation, smaller plots and higher densities. It is most obvious in the car-based development on the extremities of cities, a long way from city centres. Whatever the size of plot, the dwelling now extends over nearly the whole area except where a front set-back is required. It is a feature of low-cost housing which provides extensive floor area but not high standards of amenity and lifestyle, in marked contrast to contemporary housing in city centres. It has its origins in a situation where the plot is purchased separately from the house. The incentive is now to maximise floor area for the lowest cost, rather than to maximise amenity.

There has been little comment on what is happening in either professional or public circles, let alone any action by planning authorities to prevent it. Nevertheless, even minor amendments to local regulations on how plots are developed could bring about a significant change for the better. In the longer term, however, what is need is an awakening of a general concern for better residential design and comprehensive action to secure higher quality in the future.

\section{REFERENCES}

ABS (2004) Building Approvals, catalogue no. 8731.0, Canberra: ABS

ABS (2005) Year Book Australia no. 87, catalogue no. 1301.0, Canberra: ABS

Australian Human Rights and Equal Opportunities Commission (2007) It's About Time: Women, men work and the family

Brindley, A. (1999) Millswood Backyards: towards an insight into their role in suburban life, Unpublished dissertation submitted for the degree of Bachelor of Arts, Flinders University, Adelaide

Clark, Martin (2006) Designing for Climate: Residential Design in the Tropics (unpublished)

Gutteridge Haskin \& Davey Pty Ltd. (1989) Research Study into Siting Related Issues of Residential Development, Joint Venture For More Affordable Housing.

Halkett, Ian (1976) The Quarter-Acre Block, Canberra: Australian Institute of Urban Studies 
Hall, Tony (2007) The Disappearance of Back Yards in the Newer Australian Suburb, Urban Research program, Griffith University

Mead, Jeffrey (2000) The Suburban Backyard: Its Meaning and Use in the Contemporary Suburb. Unpublished dissertation submitted for the degree of Bachelor of Town Planning at UNSW

Relationships Forum Australia Inc (2007) An Unexpected Tragedy: Evidence for the connection between working patterns and family breakdown In Australia

Su San Lee, (1998) Natural Ventilation and Medium Density House Forms in the Tropics, PhD Thesis, Institute of Tropical Architecture, James Cook University

Syme, J. Geoffrey, Fenton, D. Mark, and Coakes, Sheridan (2001) Lot size, garden satisfaction and local park and wetland visitation, Landscape and Urban Planning 56 161-170

Timms, Peter (2006) Australia's Quarter Acre, Melbourne University Publishing 
Figure 1

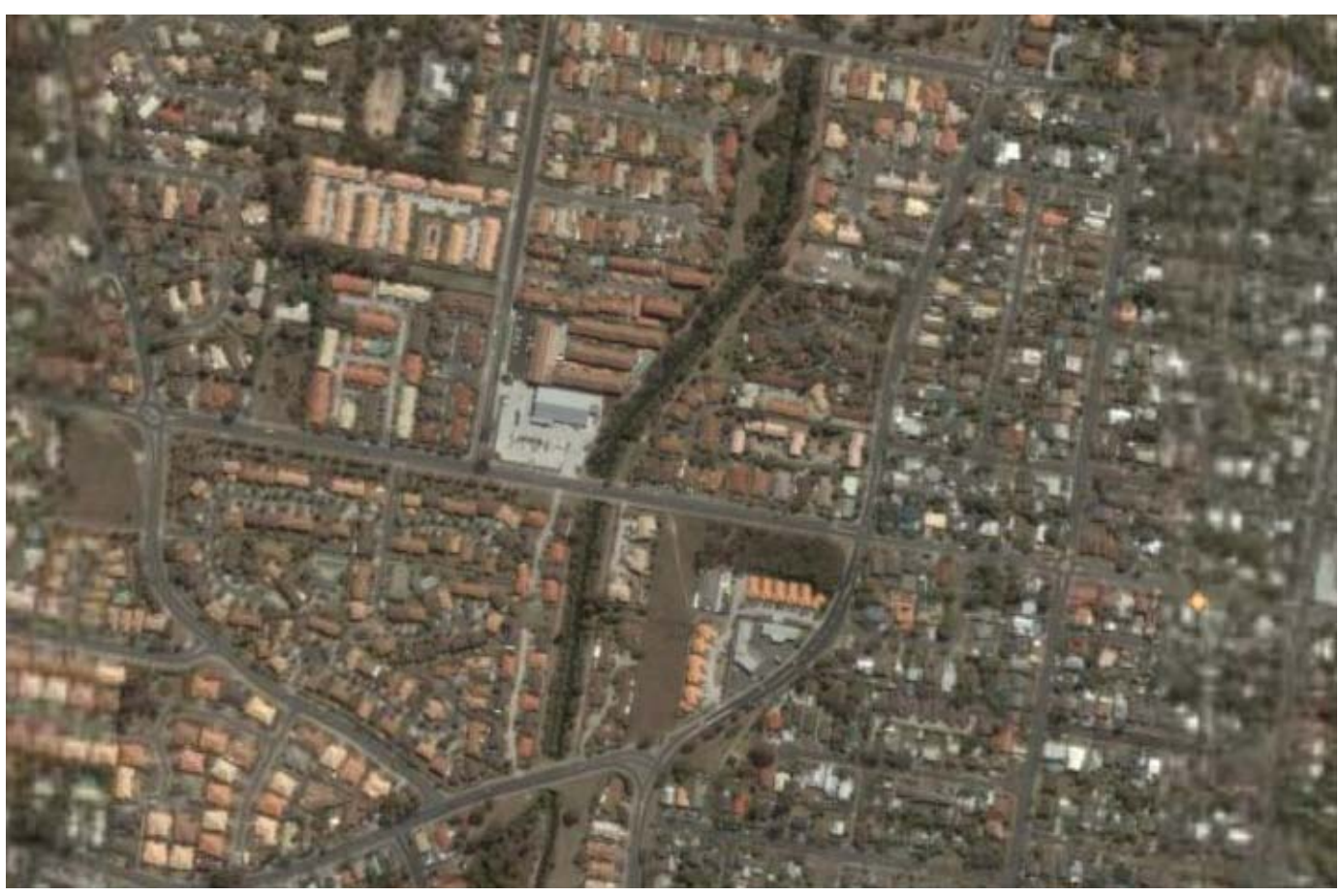

Figure 2

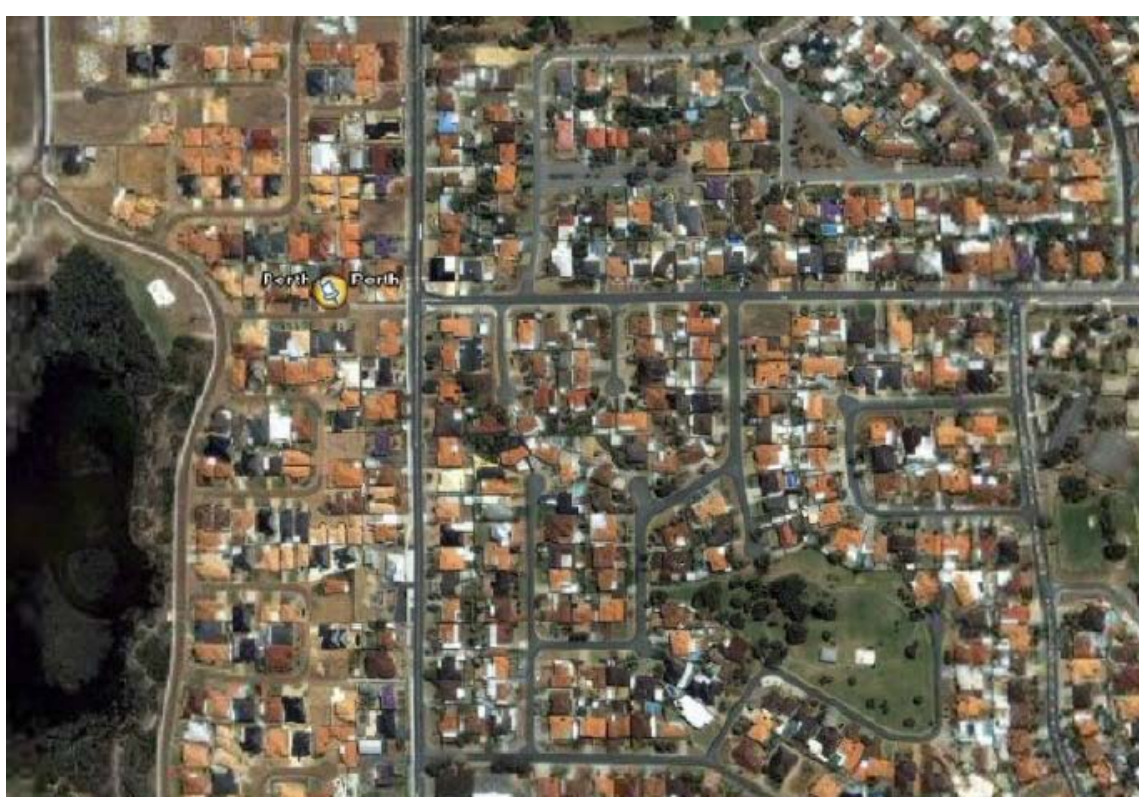


Figure 3

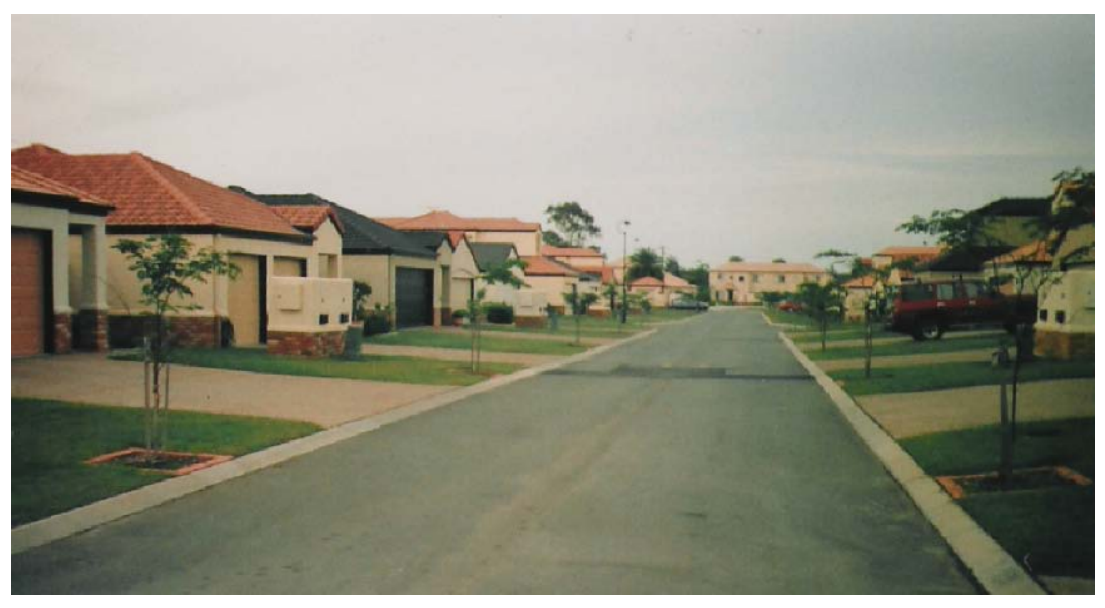

Figure 4

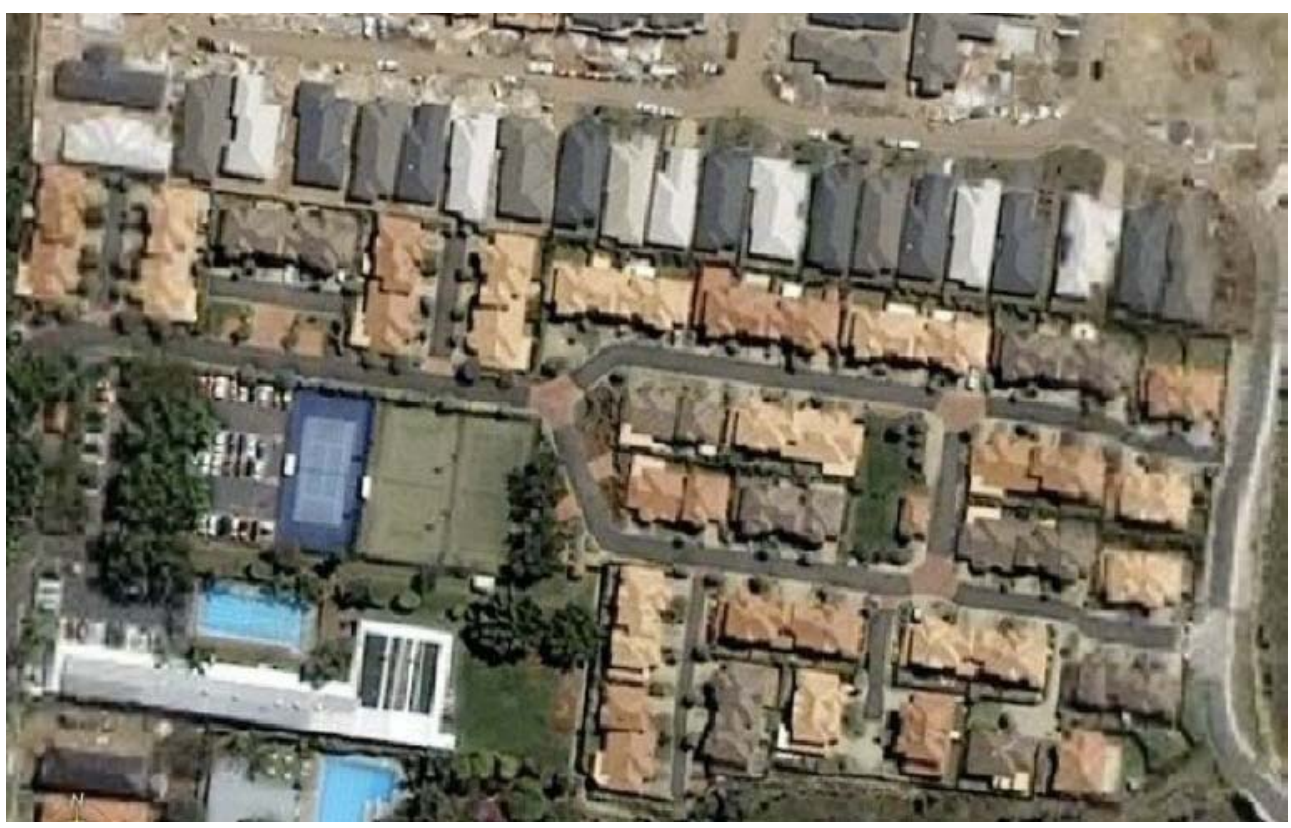


Figure 5

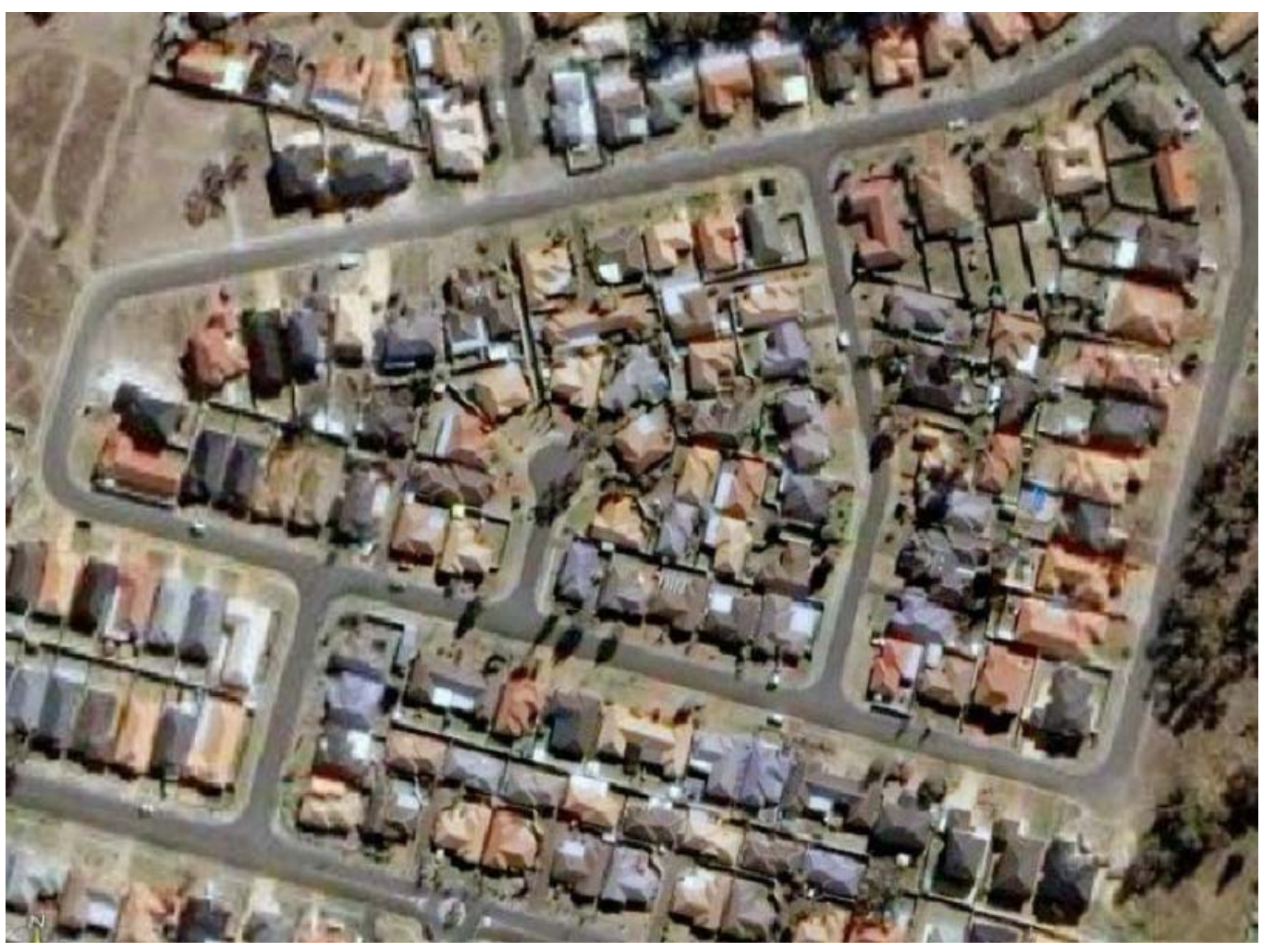

Figure 6

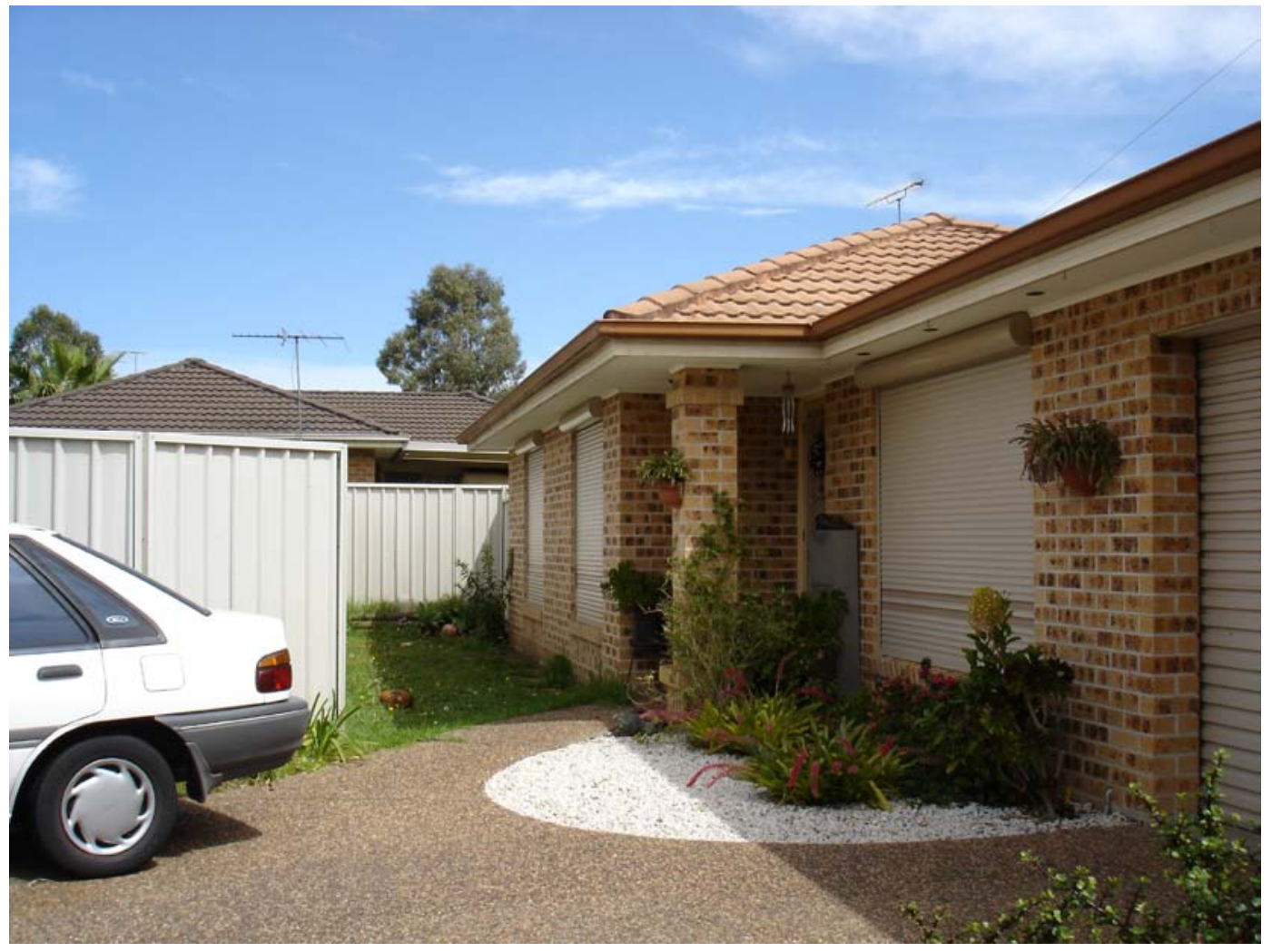


TABLE 1

\section{Older Australian Suburbs}

Brisbane - Camp Hill

Melbourne - Kew East

Sydney - Mount Druitt, Herbersham

Perth - Spearwood

\begin{tabular}{|c|c|c|c|c|c|}
\hline \multirow{2}{*}{$\begin{array}{c}\text { Net } \\
\text { density }\end{array}$} & \multicolumn{2}{|c|}{ Typical distances } & \multicolumn{2}{|c|}{ Area ranges } & \multirow{2}{*}{$\begin{array}{c}\text { Plot } \\
\text { coverage }\end{array}$} \\
\hline & $\begin{array}{c}\text { back } \\
\text { to } \\
\text { back }\end{array}$ & $\begin{array}{c}\text { back to } \\
\text { rear of } \\
\text { plot }\end{array}$ & plot & $\begin{array}{l}\text { dwelling } \\
\text { footprint }\end{array}$ & \\
\hline dph & $\mathrm{m}$ & $\mathrm{m}$ & $m^{2}$ & $\mathrm{~m}^{2}$ & $\%$ \\
\hline 11 & 30 & $10-20$ & 600 & $180-240$ & $30-40$ \\
\hline 11.6 & $29-37$ & $15-28$ & $630-840$ & $180-240$ & 30 \\
\hline 13 & 16 & $8-15$ & $448-684$ & $132-154$ & $23-30$ \\
\hline 9.3 & 27 & $14-18$ & $756-810$ & $240-300$ & $32-37$ \\
\hline
\end{tabular}

TABLE 2

\section{New Suburban Developments}

Brisbane - Carina

Brisbane - Hendra gated estate

Brisbane - Hendra

Brisbane - Forest Lake

Brisbane - Springfield Lakes

Gold Coast - Labrador

Melbourne - Meadow Heights

Sydney - Mount Druitt, Rooty Hill

Sydney - Mount Druitt, Meacher St.

Perth - Spearwood

\begin{tabular}{|c|c|c|c|c|c|}
\hline \multirow{2}{*}{$\begin{array}{c}\text { Net } \\
\text { density }\end{array}$} & \multicolumn{2}{|c|}{ Typical distances } & \multicolumn{2}{|c|}{ Area ranges } & \multirow{2}{*}{$\begin{array}{c}\text { Plot } \\
\text { coverage }\end{array}$} \\
\hline & $\begin{array}{l}\text { back } \\
\text { to } \\
\text { back }\end{array}$ & $\begin{array}{c}\text { back to } \\
\text { rear of } \\
\text { plot }\end{array}$ & plot & $\begin{array}{l}\text { dwelling } \\
\text { footprint }\end{array}$ & \\
\hline dph & $\mathrm{m}$ & $\mathrm{m}$ & $\mathrm{m}^{2}$ & $\mathrm{~m}^{2}$ & $\%$ \\
\hline 20 & $4-5$ & 3 & 330 & 200 & 61 \\
\hline 30 & $4-6$ & $<1-3$ & $180-324$ & $96-176$ & 54 \\
\hline 21 & $1-5$ & $2-3$ & $352-480$ & $253-276$ & $58-71$ \\
\hline $13-21$ & $8-11$ & $3-7$ & $260-672$ & $152-390$ & $52-69$ \\
\hline $14-16$ & $3-16$ & $<1-9$ & $225-680$ & $126-345$ & $45-65$ \\
\hline 10.5 & $3-4$ & $1.5-2$ & $720-825$ & $300-450$ & 57 \\
\hline 18.5 & $6-16$ & $2-8$ & 300-495 & $106-270$ & $44-65$ \\
\hline 19 & $3.5-10$ & $<2 ; 5.5$ & 238-375 & $168-264$ & $40-70$ \\
\hline 18 & $1.5-8$ & $<2$ & $308-456$ & $140-220$ & 47 \\
\hline 13.6 & $4-6$ & 3.5 & 594-693 & $330-447$ & $56-65$ \\
\hline
\end{tabular}

TABLE 3

\begin{tabular}{|c|c|c|c|c|c|}
\hline \multirow{2}{*}{$\begin{array}{c}\text { Net } \\
\text { density }\end{array}$} & \multicolumn{2}{|c|}{ Typical distances } & \multicolumn{2}{|c|}{ Area ranges } & \multirow[t]{2}{*}{$\begin{array}{c}\text { Plot } \\
\text { coverage }\end{array}$} \\
\hline & $\begin{array}{l}\text { back } \\
\text { to } \\
\text { back }\end{array}$ & $\begin{array}{c}\text { back to } \\
\text { rear of } \\
\text { plot }\end{array}$ & plot & $\begin{array}{l}\text { dwelling } \\
\text { footprint }\end{array}$ & \\
\hline dph & $\mathrm{m}$ & $\mathrm{m}$ & $\mathrm{m}^{2}$ & $\mathrm{~m}^{2}$ & $\%$ \\
\hline 10.3 & $24-30$ & 14 & 700 & $145-225$ & $21-32$ \\
\hline 7.4 & $24-30$ & 14 & $1000-1250$ & $300-380$ & 30 \\
\hline 9.6 & $26-32$ & $14-15$ & $851-925$ & $228-320$ & $27-35$ \\
\hline
\end{tabular}

Columbus $\mathrm{OH}$

Rocklin CA (Sacramento)

Sun City AZ (Phoenix)

\section{American Comparators}

